\title{
Unguarded tricuspid orifice with pulmonary atresia: successful radiofrequency ablation of an accessory pathway in an infant
}

\author{
Alan G Magee, Eric Rosenthal, Julian Bostock, Jaswinder Gill
}

\begin{abstract}
A male infant with the rare lesion of unguarded tricuspid orifice in the setting of pulmonary valve atresia, intact ventricular septum, and a hypoplastic right ventricle is described. The patient presented with cyanosis at 1 day old; transcutaneous oxygen saturations were between $20 \%$ and $30 \%$ in room air, and $60 \%$ in $100 \%$ inspired oxygen. Pre-excitation was found incidentally on the ECG and the potential for rapid antegrade conduction of atrial tachyarrhythmias, after eventual extended palliation with the Fontan procedure, was demonstrated at electrophysiological study. By 11 months old the patient was becoming increasingly cyanosed and interim palliation with a bidirectional cavopulmonary shunt was proposed. Successful radiofrequency ablation of the accessory pathway was performed before bidirectional cavopulmonary shunt, which would have prevented access to the heart via the superior vena cava. Difficulty with femoral venous
\end{abstract}

25 July 1997

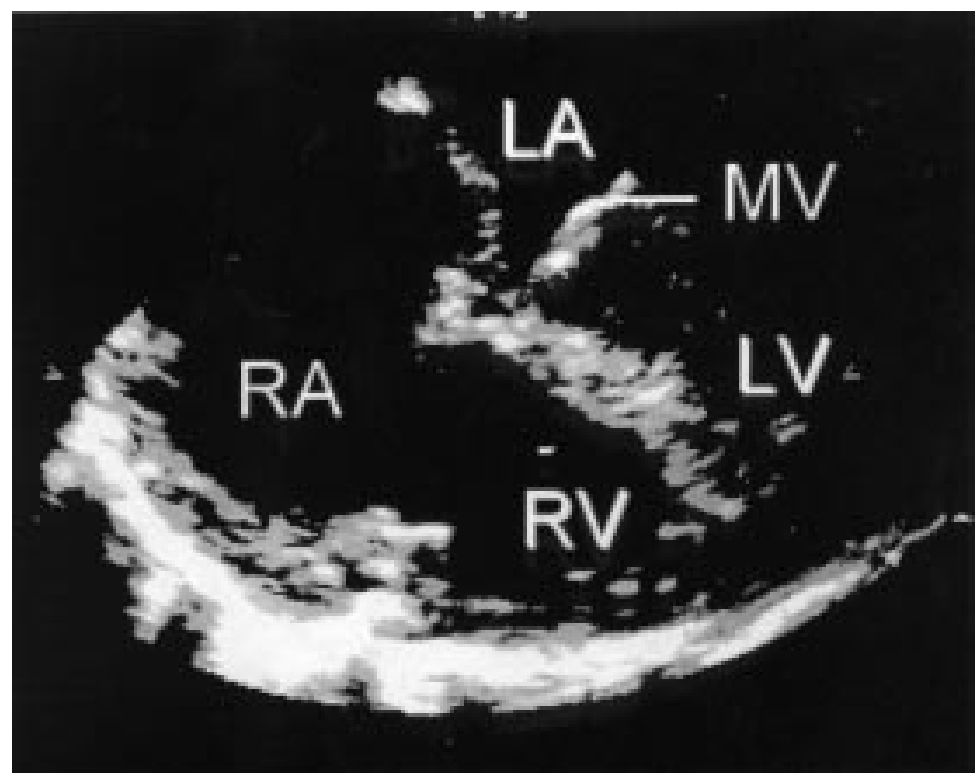

Figure 1 Transoesophageal echocardiogram in the transverse plane, showing absence of tricuspid valve tissue. $R A$, right atrium; $L A$, left atrium; $R V$, right ventricle; $L V$, left ventricle; $M V$, mitral valve (closed in diastole). access because of previous occlusion of a femoral vein was overcome by the use of $2 \mathrm{~F}$ pacing electrodes and a $5 \mathrm{~F}$ ablation catheter.

(Heart 1998;79:101-103)

Keywords: radiofrequency ablation; accessory pathway; unguarded tricuspid orifice

Accessory atrioventricular (AV) pathways are often found in association with Ebstein's anomaly of the tricuspid valve. ${ }^{1}$ Such pathways are usually right sided, are often multiple, ${ }^{2}$ and the resultant supraventricular tachycardias may be difficult to manage medically. Successful interruptions of such pathways have been described using both surgical ${ }^{3}$ and catheter techniques. $^{4}$

An integral part of Ebstein's malformation is dysplasia of the tricuspid valve leaflets. Rarely, the tricuspid orifice is completely devoid of leaflet tissue and this so called unguarded tricuspid orifice may be difficult to differentiate from some forms of Ebstein's anomaly. ${ }^{56}$ Absence of a defined tricuspid valve ring may make radiofrequency ablation of bypass tract tissue technically difficult.

We describe a patient with an unguarded tricuspid orifice, pulmonary atresia, and intact ventricular septum who was incidentally found to have pre-excitation on ECG. The accessory pathway conducted antegradely at rates of over 360 beats/min. Successful radiofrequency ablation was performed before interim palliation with a bidirectional cavopulmonary shunt.

\section{Case report}

A male infant presented with cyanosis at 1 day old. Transcutaneous oxygen saturations were between $20 \%$ and $30 \%$ in room air and rose to $60 \%$ in $100 \%$ inspired oxygen. He was managed with mechanical ventilation and prostaglandin $\mathrm{E}_{2}$ infusion with improvement in the oxygen saturation to $80 \%$. An enlarged heart was noted on chest radiography and electrocardiography showed sinus rhythm at a rate of 162 beats/min, right atrial hypertrophy, a mean frontal QRS axis of $-62^{\circ}$, and preexcitation. Echocardiography revealed the diagnosis of pulmonary atresia with intact ventricular septum, unguarded tricuspid orifice 


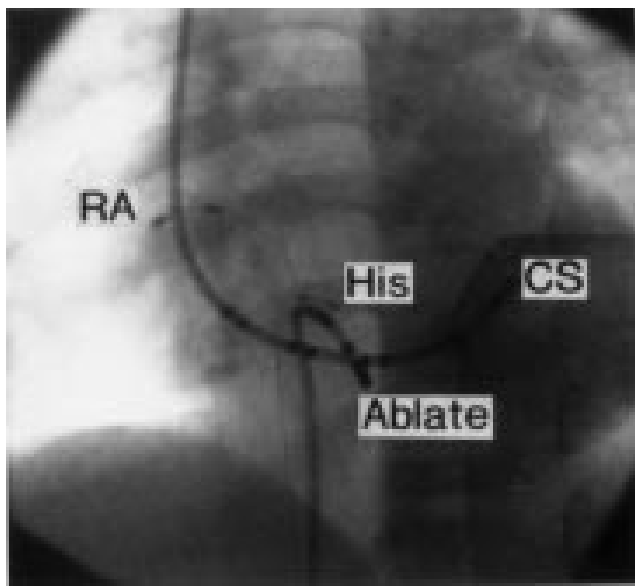

Figure 2 Still frame in the left anterior oblique projection showing decapolar lead in coronary sinus (CS), one $2 F$ bipolar lead (RA) in high right atrial position, second $2 F$ bipolar lead (His) across tricuspid orifice to record His bundle electrogram and ablation catheter (Ablate) with tip against site of earliest activation.

(fig 1), hypoplastic right ventricle, and patent foramen ovale. There was an equivocal appearance of tricuspid valve tissue anteriorly. At 2 days old, balloon atrial septostomy was attempted but was unsuccessful as the atrial septum could not be crossed. The next day a $4 \mathrm{~mm}$ central Goretex shunt was inserted between the ascending aorta and the pulmonary artery bifurcation. During this procedure, balloon atrial septostomy was successfully performed under transoesophageal echocardiographic guidance.

After initially successful palliation, the patient became increasingly cyanosed with an oxygen saturation of $66 \%$ and haemoglobin of $20.8 \mathrm{~g} / \mathrm{dl}$ by 10 months of age. Cardiac catheterisation revealed proximal right pulmonary artery narrowing at the site of shunt inser-

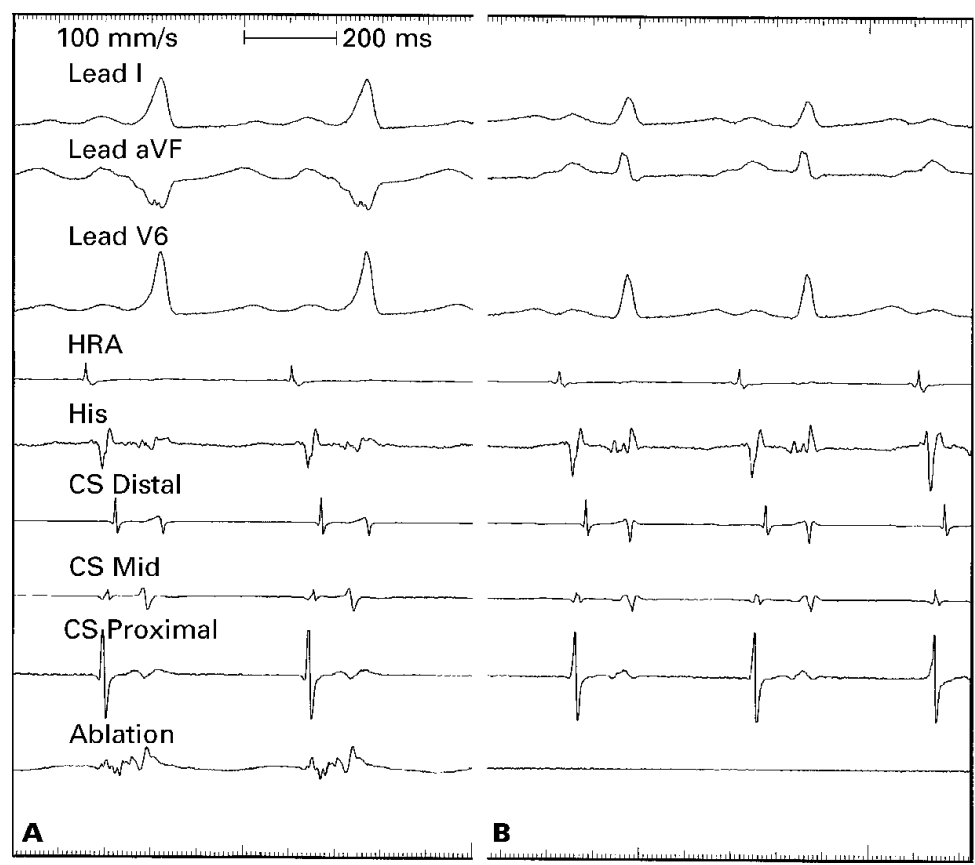

Figure 3 Surface ECG (leads 1, aVF, and V6) and intracardiac electrogram recordings before $(A)$ and after $(B)$ radiofrequency ablation. Pre-excitation has been lost in panel $B$ and the earliest site of activation is close to the proximal pair of coronary sinus electrodes. $H R A$, high right atrium; $C S$, coronary sinus. tion but good sized left and distal right pulmonary arteries. Pulmonary artery mean pressures were $12-16 \mathrm{~mm} \mathrm{Hg}$. Rapid atrial pacing revealed accessory pathway conduction at rates in excess of 360 beats/min. Radiofrequency ablation of accessory pathway tissue was proposed before performing a bidirectional cavopulmonary shunt.

The procedure was performed under general anaesthesia when the patient was 11 months old and weighed $9.1 \mathrm{~kg}$. A $5 \mathrm{~F}$ decapolar catheter (Cordis-Webster, London, UK) was placed in the coronary sinus from the left subclavian vein. As the right femoral vein was occluded, all other catheters were placed via the left femoral vein. Two $2 \mathrm{~F}$ bipolar (Osypka, Grenzach-Wyhlen, Germany) catheters were introduced; one was placed in the high right atrial position and the other across the right $\mathrm{AV}$ orifice to record the His bundle electrogram. A $5 \mathrm{~F}$ Marinr radiofrequency ablation catheter (Medtronic, San Jose, California, USA), powered by an Atakr generator (Medtronic) was advanced from the femoral vein (fig 2). A right posteroseptal pathway was identified and loss of pre-excitation noted after application of a five second burst of energy at $60^{\circ} \mathrm{C}$ (fig 3). Preexcitation returned after 20 minutes and a further three applications of energy each lasting 30 seconds were made. After this there was no return of the delta wave, and no evidence of any additional antegradely or retrogradely conducting pathways.

Three days later, the patient had a bidirectional cavopulmonary shunt with take down of the central shunt. Direct inspection of the tricuspid orifice revealed no evidence of tricuspid valve tissue. Oxygen saturations improved to just over $80 \%$ and pre-excitation had not returned after four months' follow up.

\section{Discussion}

This report describes successful radiofrequency ablation of an accessory pathway in a situation with no identifiable AV valve ring. Mapping and ablation of accessory pathways are performed where they cross the fibrous AV valve ring, which provides purchase for the catheter and lessens the degree of myocardial injury. Precise localisation of a well defined AV ring may be a problem in patients with Ebstein's disease ${ }^{4}$ and possibly in patients with an unguarded tricuspid orifice.

Pulmonary atresia, intact ventricular septum with complete absence of tricuspid valve tissue, is an extremely rare lesion that was first described in a pathological specimen by Klein in $1938 .^{7}$ Anderson et al differentiates a true unguarded orifice from the much more common Ebstein's anomaly on the basis of presence or absence of the mural leaflet of the tricuspid valve. ${ }^{6}$ The three necropsy cases they described all had a dilated right ventricle. Using echocardiography and angiography, further cases have been described usually with a hypoplastic right ventricle. ${ }^{8}$ In the present patient, echocardiography revealed tissue that was thought to represent the anterior leaflet of the tricuspid valve but on surgical inspection the orifice was completely unguarded. 
Interruption of antegrade conduction is particularly important in patients who are unsuitable for biventricular repair where the eventual management aim is extended palliation with the Fontan procedure. After this operation, there is an increasing prevalence of atrial flutter over time. ${ }^{9}$ In the presence of an accessory pathway, atrial flutter may rapidly conduct to the ventricles with a potentially lethal outcome. In such patients, interruption of the accessory pathway should take place during or before Fontan surgery. If radiofrequency catheter ablation is proposed, it should be performed before the Fontan procedure and preferably before interim palliation with the bidirectional cavopulmonary shunt procedure to allow ease of electrode catheter positioning within the coronary sinus. The use of a coronary sinus catheter may assist in the precise definition of anatomy in patients with complex congenital heart disease

In this case, successful radiofrequency ablation in the catheter laboratory avoided the need for intraoperative epicardial mapping and cryoablation that would have profoundly increased the length of the operation and possibly time on cardiopulmonary bypass. Also, ablation of the accessory pathway before surgery reduced the risk of haemodynamically compromising arrhythmias in the perioperative or postoperative periods. Mapping and ablation were facilitated by the use of $2 \mathrm{~F}$ diagnostic catheters and a $5 \mathrm{~F}$ ablation catheter as only one femoral vein was patent.

1 Watson $\mathrm{H}$. Natural history of Ebstein's anomaly of tricuspid valve in childhood and adolescence. An international co-operative study of 505 cases. Br Heart f 1974;36:417 27.

2 Smith WM, Gallagher JJ, Kerr CR, Sealy WC, Kasell JH, Benson DW, et al. The electrophysiologic basis and management of symptomatic recurrent tachycardia in patients with Ebstein's anomaly of the tricuspid valve. $\mathrm{Am}$ patients with Ebstein's anomal

3 Sealy WC, Gallagher JJ, Pritchett ELC, Wallace AG. Surgical treatment of tachyarrhythmias in patients with both an Ebstein anomaly and a Kent bundle. $\mathcal{F}$ Thorac Cardiovasc Surg 1978;75:847-53.

4 Levine JC, Walsh EP, Saul JP. Radiofrequency ablation of accessory pathways associated with congenital heart disease including heterotaxy syndrome. Am f Cardiol 1993; 72:689-93.

5 Kanjuh VI, Stevenson JE, Amplatz K, Edwards JE. Congenitally unguarded tricuspid orifice with co-existent pulmonary atresia. Circulation 1964;30:911-17.

6 Anderson RH, Silverman NH, Zuberbuhler JR. Congenitally unguarded tricuspid orifice: its differentiation from Ebstein's malformation in association with pulmonary atresia and intact ventricular septum. Paediatr Cardiol 1990;11:86-90.

7 Klein $\mathrm{H}$. Über einen seltenen Fall von herzmissbildung mit rudimentärer entwicklung des rechten ventrikels und defekt der tricuspidalklappen. Virchows Arch 1938;310:136.

8 Özkutlu S, Günal N, Caglar M, Alehan D, Güngör C. Unguarded tricuspid orifice: a rare malformation of tricuspid valve diagnosed by echocardiography. Report of two cases and review of the literature. Int $\mathcal{F}$ Cardiol 1996;56: 125-9.

9 Gelatt M, Hamilton RM, McCrindle BW, Gow RM, Williams WG, Freedom RM. Risk factors for atrial tachyarrhythmias after the Fontan operation. F Am Coll Cardiol 1994;24:1735-41. 